\title{
Gabapentin and Pregabalin and Risk of Atrial Fibrillation in the Elderly: A Population-Based Cohort Study in an Electronic Prescription Database
}

\author{
Leticia Ortiz de Landaluce ${ }^{1} \cdot$ Pere Carbonell ${ }^{1} \cdot$ Carmen Asensio $^{2} \cdot$ Núria Escoda $^{1} \cdot$ Pilar López $^{1}$. \\ Joan-Ramon Laporte ${ }^{2}$ (i)
}

Published online: 28 June 2018

(c) The Author(s) 2018

\begin{abstract}
Introduction Gabapentin and pregabalin are widely prescribed to elderly people, but data on their pharmacokinetics, safety, and efficacy in this population are scarce. Neurological adverse effects are common. Atrial fibrillation (AF) associated with their use has been described in several case reports and case series, but the incidence is unknown.

Objective The aim of this study was to assess the association between exposure to gabapentin or pregabalin and AF in the elderly.

Methods Patients $\geq 65$ years of age starting treatment with either gabapentin or pregabalin between January 1 and March 31,2015 , free of cardiovascular disease, and who did not receive the alternate study medications were studied. They were compared with patients who initiated treatment with an analgesic opiate or with alprazolam or diazepam. The two primary outcome variables were a first claim of an oral anticoagulant plus an antiarrhythmic drug (OAC + AA), or of an oral anticoagulant or an antiplatelet agent plus an antiarrhythmic drug (OAC/APA + AA), in the 3 months after treatment initiation. Results Compared with opiate analgesics, both gabapentin and pregabalin were associated with an increased risk of initiating OAC/APA + AA. The incidence was 6 of 668 (9.0 per 1000 patients) with gabapentin, versus 12 of 3889 (3.1 per 1000) with opiates, relative risk (RR) 2.91 (95\% confidence interval [CI] 1.10-7.73), and for pregabalin it was 6 of 698 (8.6 per 1000) RR 2.79 (95\% CI 1.05-7.40). The comparison with alprazolam/diazepam gave similar results. The risks did not vary
\end{abstract} by age, sex, or co-treatment with NSAIDs, and they increased with dose.

Conclusion In elderly patients free of cardiovascular disease, an association between new exposure to gabapentin or pregabalin and initiating treatment for AF was found. These results should be confirmed in other studies.

\section{Key Points}

Gabapentin and pregabalin are used for various indications, mainly low back pain and other painful conditions. In randomized clinical trials they have shown uncertain efficacy and common neurological adverse effects.

Electronic supplementary material The online version of this article (https://doi.org/10.1007/s40264-018-0695-6) contains supplementary material, which is available to authorized users.

Joan-Ramon Laporte

jrl@icf.uab.cat

1 Gerència de Prestacions Farmacèutiques i Accés al Medicament, Servei Català de la Salut, Travessera de Les Corts 131-159, Edifici Olimpia, 08028 Barcelona, Spain

2 Fundació Institut Català de Farmacologia (FICF), HU Vall d'Hebron, Universitat Autònoma de Barcelona, WHO Collaborating Centre for Research and Training in Pharmacoepidemiology, P Vall d'Hebron 119-129, 08035 Barcelona, Spain
Atrial fibrillation attributed to gabapentin and pregabalin has been described in case reports and in case series.

Compared with alternative drugs for their most common indications, starting treatment with gabapentin or pregabalin was associated with an increased rate of initiation of antithrombotic and antiarrhythmic drugs, suggesting a new diagnosis of atrial fibrillation.

Given the potential clinical and public health implications of this association, its causal nature should be investigated in studies with individual patients' data. 


\section{Introduction}

Gabapentin and pregabalin are widely and increasingly used for various approved and off-label indications [1, 2], mainly chronic low back pain with or without a neuropathic component, neuropathic pain, and anxiety. Although they are frequently used in the elderly [3-5], there are no published studies on their pharmacokinetics in subjects over the age of 65 years, and evidence of efficacy and safety is unclear [6] and limited to younger adults [7-9].

Atrial fibrillation (AF) attributed to gabapentin and to pregabalin has been described in anecdotal case reports and in case series assembled through spontaneous reporting [10-14]. Atrial fibrillation appeared within the first 3 months of treatment in $70 \%$ of cases, $>80 \%$ of patients were older than 65 years, and $6 \%$ of cases with gabapentin occurred in patients with diabetes mellitus. We examined this association in the Catalan Health Service (CHS) electronic prescription claims database.

\section{Methods}

A retrospective cohort study was performed, based on the CHS prescription claims database. The CHS provides public-funded universal healthcare coverage to the entire population of Catalonia (7.5 million inhabitants), including all prescription drugs. The electronic prescription database contains complete records of all prescriptions from all general practices and outpatient specialty clinics claimed from pharmacies in Catalonia. It includes data on patients' age, sex, the dispensed medicines, and the date of the dispensing. It does not contain systematic data on indications and clinical diagnoses [15].

In clinical practice, the most common uses of gabapentin and pregabalin are low back pain and/or sciatica with a generally ill-defined neuropathic component [2], and anxiety. We therefore aimed to compare all patients $\geq 65$ years old who initiated treatment with gabapentin or with pregabalin, with patients who initiated treatment with other drugs alternatively used in the same conditions; that is, opiate analgesics for pain, and alprazolam or diazepam for anxiety. Alprazolam and diazepam were chosen because they are the most widely used benzodiazepines for anxiety in Spain [16].

Four cohorts were studied: patients initiating treatment with gabapentin (ATC code N03AX12), with pregabalin (N03AX16), with an opiate analgesic (N02A), or with alprazolam or diazepam (N05BA12 or N05BA02), between January 1 and March 31, 2015 were considered. For each patient, the index date was the date of the first dispensing of the corresponding medication of interest. Previous use of cardiovascular medications was considered as a marker for cardiovascular disease or cardiovascular risk, and also as a potential confounding factor. Therefore, patients who had received a cardiovascular medicine (Group C of the ATC classification) or an antithrombotic agent (oral anticoagulant or antiplatelet agent; groups B01AA, B01AE, and B01AF of the ATC classification) in the 6 months before the index date were excluded.

Start of treatment with any of the study medications was defined as a claimed prescription for a patient who had not been dispensed that medication in the 6 months preceding the index date. The primary analyses were performed in patients who initiated treatment with only one of the study medications (and not with other study medications). Secondary analyses were performed including all patients who initiated treatment with each of the study drugs, including those on concomitant treatment with any of the other study medications (e.g., patients concomitantly on pregabalin and alprazolam, pregabalin and an opiate, etc.). Within each cohort, patients were stratified into three groups: those who started treatment with the medication of interest without a nonsteroidal anti-inflammatory drug (NSAID), those who started with both the medication of interest and an NSAID, and those to whom the medication of interest had been added to an NSAID that had already been dispensed in the 6 months before. The main analyses were performed considering only patients who initiated treatment with any of the medications of interest and not with an NSAID.

The outcome measure was the proportion of patients claiming a first prescription of medications specifically used in the treatment of AF in the 3 months after the date of the initial dispensing of the study drug. Several outcome variables were selected. The primary co-variables were a first claim of an oral anticoagulant (OAC, groups B01AA, $\mathrm{B} 01 \mathrm{AE}$, and B01AF of the ATC classification) plus an antiarrhythmic drug (AA, ATC code, C01B) (OAC + AA), and a first claim of an OAC or an antiplatelet agent (APA, ATC code, B01AC) plus an antiarrhythmic drug (OAC/ APA + AA). Two secondary variables were examined: a first claim of an AA, and a first claim of an OAC or an APA (OAC/APA). The secondary variable OAC/APA, with higher numbers of patients, was used for the analyses stratified by dose, age, and sex.

The cohorts of users of gabapentin, pregabalin, or any of both were compared with the cohort of opiate users and with that of alprazolam or diazepam users.

For each outcome variable, relative risks and their corresponding two-sided $95 \%$ confidence intervals (CIs) were computed using the VassarStats website for statistical computation (http://vassarstats.net). Stratified analyses were performed by age groups (65-74, 75-84, and $\geq 85$ years), by sex, and by co-treatment with NSAIDs. In order to evaluate dose-effect relationships, two dose strata were considered: $<1200$ and $\geq 1200 \mathrm{mg}$ per day for gabapentin, 
and $<150$ and $\geq 150 \mathrm{mg}$ per day for pregabalin. The outcome variables with the highest numbers of patients (i.e., $\mathrm{OAC} / \mathrm{APA}+\mathrm{AA}$ and OAC/APA) were used for dose-effect analyses.

Ethical approval was not sought, because it is not required for observational studies using anonymized nationwide registries in Catalonia. This study is registered in the European Union Electronic Register of Post-Authorisation Studies (EU PAS Register) with the number EUPAS15048.

\section{Results}

From January 1 to March 31 2015, 5402 individuals aged $\geq 65$ years initiated treatment with gabapentin, 6053 with pregabalin, 37,500 with opiate analgesics, and 19,849 with alprazolam or diazepam. Fig. S1 of the Electronic Supplementary Material (ESM) shows a flow chart on the selection of the study patients. The cohort of users of alprazolam or diazepam had higher proportions of females and of individuals in the younger age group (65-74 years of age) (Table 1).

Out of 5402 patients aged $\geq 65$ years initiating treatment with gabapentin, 4490 (83.1\%) were already on cardiovascular medications. The corresponding figure for pregabalin was $4979(82.3 \%)$.

In all four cohorts, the rates of treatment initiation with antithrombotic drugs (OAC/APA) or with OAC/APA plus an antiarrhythmic drug (OAC/APA + AA) in the 3 months after the dispensing of the medications of interest increased considerably with age, and it was higher with gabapentin and pregabalin compared with opiate analgesics or alprazolam/
Table 1 Age and sex distribution and cardiovascular comorbidity of the study cohorts

\begin{tabular}{|c|c|c|c|c|}
\hline & Gabapentin & Pregabalin & $\begin{array}{l}\text { Alprazolam } \\
\text { or diazepam }\end{array}$ & Opiates $^{\mathrm{a}}$ \\
\hline$N$ dispensed, aged $\geq 18 \mathrm{y}$ & 47,104 & 63,423 & 289.654 & 223,614 \\
\hline$N$ aged $\geq 65$ y $(\%)$ & $25,759(54.7)$ & $30,811(48.6)$ & $98,323(33.9)$ & $129,243(57.8)$ \\
\hline$N$ aged $\geq 65 \mathrm{y}$ initiating treatment & 5402 & 6053 & $18,119^{\mathrm{b}}$ & $33,343^{b}$ \\
\hline Already on CV medication, n (\%) & $4490(83.1)$ & $4979(82.3)$ & $14,231(78.5)$ & $27,653(83.9)$ \\
\hline Naïve to CV medication, $\mathrm{n}(\%)$ & $912(16.9)$ & $1074(17.7)$ & $3888(21.5)$ & $5690(17.1)$ \\
\hline Units per patient (mean) ${ }^{\mathrm{c}}$ & 2.0 & 2.6 & 1.9 & 2.7 \\
\hline Female, $\%$ & 65.5 & 65.6 & 71.2 & 68.2 \\
\hline Aged $65-74, \%$ & 60.6 & 65.1 & 73.5 & 62.1 \\
\hline Aged $75-84, \%$ & 29.7 & 26.8 & 19.8 & 27.5 \\
\hline Aged $\geq 84, \%$ & 9.6 & 8.1 & 6.7 & 10.4 \\
\hline
\end{tabular}

$C V$ cardiovascular

${ }^{a}$ In defined daily doses (DDDs), tramadol made up 52\% of total consumption, followed by fentanyl (26\%), and other opiates (22\%; morphine, oxycodone, tapentadol, etc.)

${ }^{\mathrm{b}}$ Patients who initiated treatment during the study period, free of gabapentin and pregabalin during the first month and in the 6 months before

${ }^{c}$ During the first 3 months of exposure
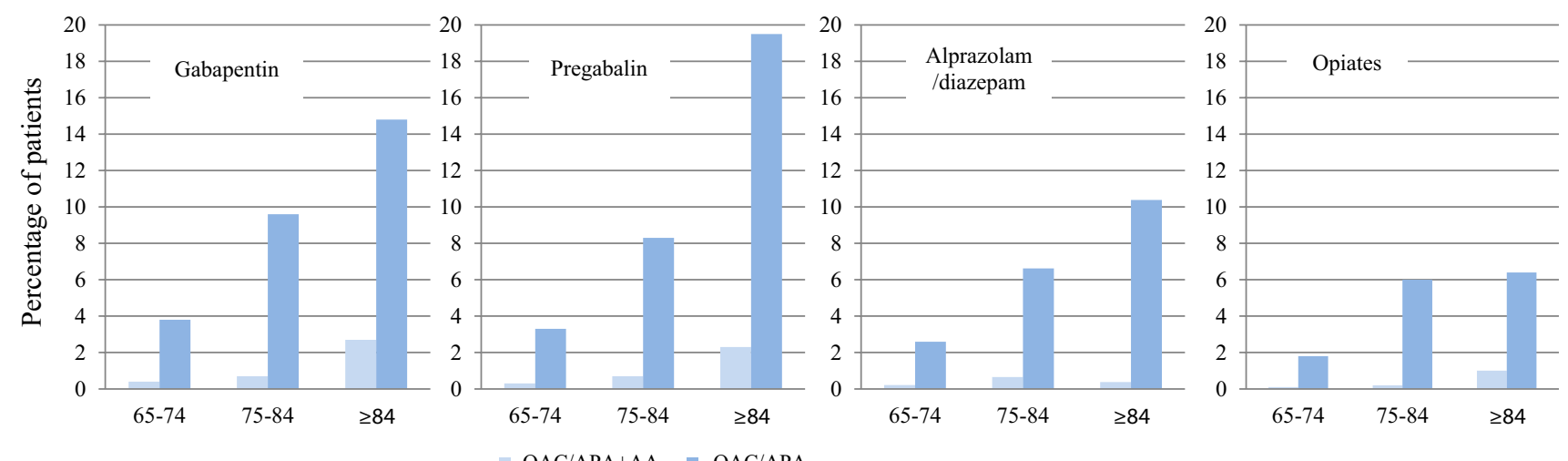

Fig. 1 Effect of age (y) on the rate of two outcomes in each cohort. $O A C / A P A+A A$ oral anticoagulant or antiplatelet drug plus antiarrhythmic drug, $O A C / A P A$ oral anticoagulant or antiplatelet drug 
diazepam (Fig. 1). There were no differences between males and females.

The incidence rates of initiating OAC/APA + AA were 3.1 per 1000 exposed patients for alprazolam/diazepam, 3.1 for opiate analgesics, 9.0 for gabapentin, and 8.6 for pregabalin (relative risk [RR] 2.91 [95\% CI 1.10-7.73] for gabapentin, and RR 2.79 [95\% CI 1.05-7.40] for pregabalin, compared with opiate analgesics). The incidence rates of initiating OAC + AA were 1.8 per 1000 patients for opiates, 3.0 for alprazolam/diazepam, 6.0 for gabapentin, and 5.1 for pregabalin. Table 2 shows the risks of the primary and the secondary variables. All the risk estimates were increased, and their magnitudes were similar for gabapentin and pregabalin. However, for the primary variable $(\mathrm{OAC}+\mathrm{AA})$ they did not reach statistical significance due to low numbers of patients, both in comparison with opiate analgesics and with alprazolam/diazepam. There were no differences in the risk estimates in the three age strata, nor by sex (Table S1 of the ESM). The results did not vary materially when all patients under the study medications were considered, including those who were concomitantly on more than one study drug (Table S2 of the ESM).

In each cohort, the results among patients who initiated treatment with the medication of interest added to an NSAID or at the same time as an NSAID were not different from those in patients who were not on NSAIDs (data not shown).

There were 561 patients treated with gabapentin at doses $<1200 \mathrm{mg}$ per day (84\%), and $107(16 \%)$ with $\geq 1200 \mathrm{mg}$ per day. For pregabalin, 579 patients received $<150 \mathrm{mg}$ per day $(83 \%)$ and $119(17 \%)$ received $>150 \mathrm{mg}$ per day. The relative risks of the variables were twice as high among patients receiving the higher doses, compared with those on lower doses (Table 3).

\section{Discussion}

We found that, compared with users of opiates and of alprazolam or diazepam, users of both gabapentin and pregabalin were at increased risk of initiating treatment with medicines specifically used in the management of AF within 3 months after treatment initiation. The RR estimates were consistent for the primary and secondary variables and across the age, sex, and co-medication strata, and they showed a dose-response trend.

$\mathrm{AF}$ associated with gabapentin or pregabalin has not been described in reports of randomized clinical trials (RCTs) or in systematic reviews of RCTs. The reason may be that

Table 2 Use of drugs for atrial fibrillation

\begin{tabular}{|c|c|c|c|c|}
\hline & $\mathrm{OAC}+\mathrm{AA}^{\mathrm{a}}$ & $\mathrm{OAC} / \mathrm{APA}+\mathrm{AA}^{\mathrm{b}}$ & $\mathrm{AA}^{\mathrm{c}}$ & OAC/APA $^{\mathrm{d}}$ \\
\hline \multicolumn{5}{|c|}{ Compared with opiate analgesics } \\
\hline Opiates & $\begin{array}{l}1.00 \text { (Reference category) } \\
(7 / 3889)\end{array}$ & $\begin{array}{l}1.00 \text { (Reference category) } \\
(12 / 3889)\end{array}$ & $\begin{array}{l}1.00 \text { (Reference category) } \\
(21 / 3889)\end{array}$ & $\begin{array}{l}1.00 \text { (Reference category) } \\
(148 / 3889)\end{array}$ \\
\hline Gabapentin & $\begin{array}{l}3.33(0.98-11.33) \\
(4 / 668)\end{array}$ & $\begin{array}{l}2.91(1.10-7.73) \\
(6 / 668)\end{array}$ & $\begin{array}{l}2.50(1.15-5.42) \\
(9 / 668)\end{array}$ & $\begin{array}{l}2.60(1.57-2.82) \\
(58 / 668)\end{array}$ \\
\hline Pregabalin & $\begin{array}{l}2.39(0.62-9.21) \\
(3 / 698)\end{array}$ & $\begin{array}{l}2.79(1.05-7.40) \\
(6 / 698)\end{array}$ & $\begin{array}{l}1.86(0.79-4.35) \\
(7 / 698)\end{array}$ & $\begin{array}{l}1.84(1.36-2.49) \\
(53 / 698)\end{array}$ \\
\hline $\mathrm{GP} / \mathrm{PG}^{\mathrm{e}}$ & $\begin{array}{l}2.85(1.00-8.10) \\
(7 / 1366)\end{array}$ & $\begin{array}{l}2.85(1.28-6.32) \\
(12 / 1366)\end{array}$ & $\begin{array}{l}2.17(1.14-4.14) \\
16 / 1366)\end{array}$ & $\begin{array}{l}1.97(1.55-2.50) \\
(111 / 1366)\end{array}$ \\
\hline \multicolumn{5}{|c|}{ Compared with benzodiazepines } \\
\hline $\mathrm{AL} / \mathrm{DZ}{ }^{\mathrm{f}}$ & $\begin{array}{l}1.00 \text { (Reference category) } \\
(8 / 2.640)\end{array}$ & $\begin{array}{l}1.00 \text { (Reference category) } \\
(10 / 2640)\end{array}$ & $\begin{array}{l}1.00 \text { (Reference category) } \\
(12 / 2640)\end{array}$ & $\begin{array}{l}1.00 \text { (Reference category) } \\
(128 / 2640)\end{array}$ \\
\hline Gabapentin & $\begin{array}{l}1.96(0.59-6.50) \\
(4 / 668)\end{array}$ & $\begin{array}{l}2.37(0.86-6.50) \\
(6 / 668)\end{array}$ & $\begin{array}{l}2.92(1.24-6.91) \\
(9 / 668)\end{array}$ & $\begin{array}{l}1.79(1.33-2.41) \\
(58 / 668)\end{array}$ \\
\hline Pregabalin & $\begin{array}{l}1.42(0.38-5.33) \\
(3 / 698)\end{array}$ & $\begin{array}{l}2.27(0.83-6.22) \\
(6 / 698)\end{array}$ & $\begin{array}{l}2.21(0.87-5.58) \\
(7 / 698)\end{array}$ & $\begin{array}{l}1.57(1.15-2.13) \\
(53 / 698)\end{array}$ \\
\hline $\mathrm{GP} / \mathrm{PG}^{\mathrm{e}}$ & $\begin{array}{l}1.69(0.61-4.65) \\
(7 / 1366)\end{array}$ & $\begin{array}{l}2.32(1.00-5.35) \\
(12 / 1366)\end{array}$ & $\begin{array}{l}2.58(1.22-5.43) \\
(16 / 1366)\end{array}$ & $\begin{array}{l}1.68(1.31-2.14) \\
(111 / 1366)\end{array}$ \\
\hline
\end{tabular}

${ }^{\mathrm{a}} \mathrm{OAC}+\mathrm{AA}$ : Patients who started treatment with an oral anticoagulant plus an antiarrhythmic drug in the 3 months after treatment initiation with the study drug

${ }^{\mathrm{b}} \mathrm{OAC} / \mathrm{APA}+\mathrm{AA}$ : Patients who started treatment with an oral anticoagulant or an antiplatelet agent plus an antiarrhythmic drug in the 3 months after treatment initiation with the study drug

${ }^{\mathrm{c}} \mathrm{AA}$ : Patients who started treatment with an antiarrhythmic drug in the 3 months after treatment initiation with the study drug

${ }^{\mathrm{d}} \mathrm{OAC}$ : Patients who started treatment with an oral anticoagulant in the 3 months after treatment initiation with the study drug

${ }^{\mathrm{e}} \mathrm{GP} / \mathrm{PG}$ : gabapentin or pregabalin

${ }^{\mathrm{f}} \mathrm{AL} / \mathrm{DZ}$ : alprazolam or diazepam 
Table 3 Dose of gabapentin and pregabalin and risk of initiating antithrombotic treatment, alone or simultaneously with an antiarrhythmic drug

\begin{tabular}{|c|c|c|}
\hline & ${\mathrm{OAC} / \mathrm{APA}^{\mathrm{a}}}$ & $\mathrm{OAC} / \mathrm{APA}+\mathrm{AA}^{\mathrm{b}}$ \\
\hline \multicolumn{3}{|l|}{ Compared with opiates } \\
\hline \multicolumn{3}{|l|}{ Gabapentin } \\
\hline$<1200$ mg per day & $\begin{array}{l}1.90(1.37-2.63) \\
(44 / 561)\end{array}$ & $\begin{array}{l}2.32(0.75-7.16) \\
(4 / 561)\end{array}$ \\
\hline$\geq 1200 \mathrm{mg}$ per day & $\begin{array}{l}3.17(1.90-5.30) \\
(14 / 107)\end{array}$ & $\begin{array}{l}6.07(1.38-26.80) \\
(2 / 107)\end{array}$ \\
\hline All & $\begin{array}{l}2.60(1.57-2.82) \\
(58 / 668)\end{array}$ & $\begin{array}{l}2.92(1.10-7.75) \\
(6 / 668)\end{array}$ \\
\hline \multicolumn{3}{|l|}{ Pregabalin } \\
\hline$<150 \mathrm{mg}$ per day & $\begin{array}{l}1.51(1.06-2.15) \\
(36 / 579)\end{array}$ & $\begin{array}{l}2.24(0.73-6.94) \\
(4 / 579)\end{array}$ \\
\hline$\geq 150 \mathrm{mg}$ per day & $\begin{array}{l}3.46(2.17-5.53) \\
(17 / 119)\end{array}$ & $\begin{array}{l}5.46(1.24-24.13) \\
(2 / 119)\end{array}$ \\
\hline All & $\begin{array}{l}1.84(1.36-2.49) \\
(53 / 698)\end{array}$ & $\begin{array}{l}2.79(1.05-7.42) \\
(6 / 698)\end{array}$ \\
\hline \multicolumn{3}{|c|}{ Gabapentin or pregabalin } \\
\hline Low dose & $\begin{array}{l}1.70(1.31-2.22) \\
(80 / 1140)\end{array}$ & $\begin{array}{l}2.28(0.93-5.56) \\
(8 / 1140)\end{array}$ \\
\hline High dose & $\begin{array}{l}3.33(2.31-4.78) \\
(31 / 226)\end{array}$ & $\begin{array}{l}5.76(1.87-17.69) \\
(4 / 226)\end{array}$ \\
\hline All & $\begin{array}{l}1.97(1.55-2.50) \\
(111 / 1366)\end{array}$ & $\begin{array}{l}2.85(1.29-6.34) \\
(12 / 1.366)\end{array}$ \\
\hline \multicolumn{3}{|c|}{ Compared with benzodiazepines } \\
\hline \multicolumn{3}{|l|}{ Gabapentin } \\
\hline$<1200 \mathrm{mg}$ per day & $\begin{array}{l}1.62(1.16-2.25) \\
(44 / 561)\end{array}$ & $\begin{array}{l}1.89(0.59-6.00) \\
(4 / 561)\end{array}$ \\
\hline$\geq 1200 \mathrm{mg}$ per day & $\begin{array}{l}2.70(1.61-4.52) \\
(14 / 107)\end{array}$ & $\begin{array}{l}4.86(1.08-21.90) \\
(2 / 107)\end{array}$ \\
\hline All & $\begin{array}{l}1.79(1.33-2.41) \\
(58 / 668)\end{array}$ & $\begin{array}{l}2.37(0.86-6.50) \\
(6 / 668)\end{array}$ \\
\hline \multicolumn{3}{|l|}{ Pregabalin } \\
\hline$<150 \mathrm{mg}$ per day & $\begin{array}{l}1.21(0.84-1.73) \\
(36 / 579)\end{array}$ & $\begin{array}{l}1.82(0.57-5.78) \\
(4 / 579)\end{array}$ \\
\hline$\geq 150 \mathrm{mg}$ per day & $\begin{array}{l}2.95(1.84-4.72) \\
(17 / 119)\end{array}$ & $\begin{array}{l}4.45(0.99-20.10) \\
(2 / 119)\end{array}$ \\
\hline All & $\begin{array}{l}1.73(1.31-2.28) \\
(53 / 698)\end{array}$ & $\begin{array}{l}2.27(0.83-6.22) \\
(6 / 698)\end{array}$ \\
\hline \multicolumn{3}{|c|}{ Gabapentin or pregabalin } \\
\hline Low dose & $\begin{array}{l}1.45(1.10-1.90) \\
(80 / 1140)\end{array}$ & $\begin{array}{l}1.86(0.74-4.70) \\
(8 / 1140)\end{array}$ \\
\hline High dose & $\begin{array}{l}2.83(1.96-4.09) \\
(31 / 226)\end{array}$ & $\begin{array}{l}4.69(1.48-14.84) \\
(4 / 226)\end{array}$ \\
\hline All & $\begin{array}{l}1.68(1.31-2.14) \\
(111 / 1366)\end{array}$ & $\begin{array}{l}2.32(1.00-5.35) \\
(12 / 1366)\end{array}$ \\
\hline
\end{tabular}

${ }^{a}$ OAC/APA: Patients who started treatment with an oral anticoagulant or an antiplatelet agent in the 3 months after treatment initiation with the study drug

${ }^{\mathrm{b}} \mathrm{OAC} / \mathrm{APA}+\mathrm{AA}$ Patients who started treatment with an oral anticoagulant or antiplatelet agent plus antiarrhythmic drug in the 3 months after treatment initiation with the study drug participants in placebo-controlled RCTs with gabapentin [8] or pregabalin [9] had a mean age of 55 years. In contrast, in a series of patients with AF possibly induced by gabapentin [13] or pregabalin [14], $>80 \%$ were older than 60 years.

Gabapentin and pregabalin exhibit L-type calcium channel antagonism and attenuate calcium influx, which can explain unwanted electrophysiological effects. Both drugs are eliminated by renal excretion as unchanged drugs, and both Summary of Product Characteristics (SPCs) state that elderly patients may require a dose reduction $[17,18]$. However, pharmacokinetic studies in subjects over the age of 65 years have not been reported [7].

Our study covered the whole population, so that representativeness of the study population is not a concern. Patients on cardiovascular medications were excluded and the analyses were restricted to incident users, so that the potential biases and confounding that would have been introduced by the inclusion of patients with high cardiovascular risk and prevalent users were avoided. Patients initiating treatment with gabapentin or with pregabalin were compared with patients initiating treatment with two different alternative therapeutic options in the most common indications of gabapentinoids. The comparison with both opiates and benzodiazepines showed increases of risk in the same direction and of similar magnitudes. The results are biologically plausible, and they were consistent for the primary and the secondary variables and across all age, sex, and NSAID co-treatment strata. A dose-effect trend was found. A material increase in risk with alprazolam or diazepam was not recorded. These features indicate that users of gabapentin and pregabalin are at increased risk of initiating antithrombotic and antiarrhythmic drugs, probably prompted by a diagnosis of AF.

Our study has several limitations. Those which merit more emphasis relate to the lack of clinical details on the participants and to the validity of the outcome variables used. The lack of clinical details precluded describing their clinical course and their prognosis and adjusting for potential clinical confounding factors such as the indication for use and co-morbidities. The outcome variables were surrogate markers of AF. A recent study performed in the French healthcare databases has suggested that the initiation of an oral anticoagulant and an antiarrhythmic drug $(\mathrm{OAC}+\mathrm{AA})$ recorded in the national pharmaceutical benefits database (SNIRAM) is the strongest predictor for confirmed AF [19]. In our study, the number of patients initiating $\mathrm{OAC}+\mathrm{AA}$ was low. However, when patients exposed to either gabapentin or pregabalin were considered, the risk was significantly increased with respect to both opiate analgesics and alprazolam/diazepam. Due to lower numbers of exposed patients, our stratified age, sex, and dose-response analyses were based on the variables OAC/APA and OAC/ APA + AA, which may be less specific for AF but included 
higher numbers of patients. For these reasons, our results should be regarded as hypothesis generating.

It is generally considered that the use of prescription claims as proxy variables for the clinical conditions under study can limit the validity of the results. However, as an outcome variable, the prescription of an oral antithrombotic and/or an antiarrhythmic agent is at least as hard as an often tentative diagnosis of AF in the medical record. The use of antiarrhythmic drugs without antithrombotic medication, which may reflect prescribing for a patient with AF with a low risk of stroke, was also significantly increased in users of gabapentin or pregabalin.

If the association between exposure to gabapentinoids and $\mathrm{AF}$ is a causal one, its public health impact could be higher than suggested by our data, at least for three reasons. First, although the respective SPCs warn "caution in cardiovascular patients" $[17,18]$, more than $80 \%$ of the new users of gabapentin or pregabalin were already on at least one cardiovascular medication, which is a marker of cardiovascular risk. In order to avoid confounding, we excluded these high-risk patients from the study. Second, in large series of cases reported to the FDA, 70-80\% of patients with newly diagnosed AF attributed to gabapentin or pregabalin had developed the condition during the first 3 months of treatment $[13,14]$, suggesting that additional cases can appear $>3$ months after treatment initiation. Third, up to $30 \%$ of cases of AF may take time to be diagnosed [20,21] and many of those who are diagnosed do not receive full anticoagulation initially [22], so that the actual number of cases of AF is probably higher than the number of patients initiating treatment with an antithrombotic drug. Conversely, an episode of AF occurring before the prescription of gabapentin or pregabalin may have been initially overlooked or left untreated, but diagnosed and treated some weeks after the gabapentinoid was prescribed, and this would overestimate the risk.

In recent years, the consumption of gabapentin and pregabalin has increased steadily [1, 3-5, 23]. Pain appears to be their most common indication [2, 24]. Although their efficacy in neuropathic pain is modest at best, they are widely used for conditions in which the neuropathic component is difficult to establish. In industry-sponsored placebo-controlled RCTs in neuropathic pain, gabapentin was ineffective at doses $<1200 \mathrm{mg}$ per day [8] and pregabalin at doses $<150 \mathrm{mg}$ per day [9]. The best (lowest) number needed to treat for at least a $50 \%$ pain relief over baseline with pregabalin was 3.9, but only with a dose of $600 \mathrm{mg}$ daily, which in turn was associated with a withdrawal rate of $19 \%$ (mainly due to dizziness and somnolence) [9]. In a recent rigorously conducted placebo-controlled trial, pregabalin at doses of 150-600 mg daily was ineffective to mitigate pain or disability in patients with painful sciatica, and it was associated with a 3 -fold increase in the incidence of dizziness [6]. A recent systematic review on gabapentinoids in chronic low back pain concluded that limited evidence shows a significant risk of adverse effects without any demonstrated benefit [25]. In our study, $84 \%$ of patients on gabapentin or pregabalin had been prescribed $<1200 \mathrm{mg}$ per day or $150 \mathrm{mg}$ per day, respectively, and the risks of the main outcome variables were already increased with these lower doses.

Gabapentin was approved in 1993 as adjunctive therapy for partial complex seizures. Heavy promotion for unapproved indications pushed its sales in the US from US\$98 million in 1995 to nearly US\$3 billion in 2004 [26]. In that year gabapentin lost its patent, but Pfizer launched pregabalin, not only for epilepsy but also for the wider, softer, and better selling indications of anxiety and neuropathic pain. Gabapentin and pregabalin are being prescribed off-label for painful conditions, mainly low back pain [2], where the neuropathic component is difficult to establish. In 2016 pregabalin reached global sales of US $\$ 5435 \mathrm{M}$, and it ranked 12th in the list of global top-selling pharmaceuticals [27]. Between 2012 and 2016, prescriptions of gabapentin increased from 39 to 64 million, and sales of pregabalin increased by more than 2.4-fold in the US [1]. Our results contrast with the fact that after decades of wide and rising clinical use of gabapentin and pregabalin, only a few case reports and case series of AF attributed to these drugs have been described.

\section{Conclusion}

In summary, we found that, despite warnings of caution in the elderly in the respective SPCs, gabapentin and pregabalin were predominantly prescribed to patients with cardiovascular risk, generally at doses too low to be effective. In addition, we found a signal suggesting that in elderly patients free of cardiovascular disease, exposure to gabapentin or to pregabalin may be associated with an increased risk of AF. The incidence might be substantially higher than is stated in the respective SPCs. This association should be confirmed by a review of the company's postmarketing surveillance data and in studies with validated clinical diagnoses. Meanwhile, given the poor efficacy and benefit/risk ratio of these drugs in their most common indications in clinical practice, prescribers should avoid them, particularly in the elderly and in patients with established or suspected cardiovascular disease or with high cardiovascular risk. In clinical practice, it seems advisable to stop gabapentin or pregabalin in any exposed patient presenting with AF.

Acknowledgements Luisa Ibáñez (FICF), Mònica Sabaté (FICF), and Xavier Vidal (FICF) reviewed the draft paper and formulated comments. Xavier Vidal advised on statistical analysis. Héctor Carmona (FICF) gave support in statistical analyses and manuscript editing. Antoni Gilabert gave institutional support. 


\section{Compliance with Ethical Standards}

Funding This work is part of a project on safety of electronic prescribing of the Catalan Health Service and Fundació Institut Català de Farmacologia.

Conflicts of interest Leticia Ortiz, Pere Carbonell, Carmen Asensio, Núria Escoda, Pilar López, and Joan-Ramon Laporte have no conflicts of interest that are directly relevant to the content of this study.

Disclaimer The views expressed are solely those of the authors and do not necessarily represent the position of, nor imply endorsement from, the Catalan Health Service.

Open Access This article is distributed under the terms of the Creative Commons Attribution-NonCommercial 4.0 International License (http://creativecommons.org/licenses/by-nc/4.0/), which permits any noncommercial use, distribution, and reproduction in any medium, provided you give appropriate credit to the original author(s) and the source, provide a link to the Creative Commons license, and indicate if changes were made.

\section{References}

1. Goodman CW, Brett AS. Gabapentin and pregabalin for painis increased prescribing a cause for concern? N Engl J Med. 2017;377:411-4.

2. Härmark L, van Puijenbroek E, Straus S, van Grootheest K. Intensive monitoring of pregabalin. Results from an observational, web-based, prospective cohort. Study in the Netherlands using patients as a source of information. Drug Saf. 2011;34:221-31.

3. Ferrer-Argeles P, Rafaniello C, Sabaté M, Ballarin E, Coma A, Zara C, et al. Cross-national comparison of antiepileptic drug use: Catalonia, Denmark and Norway, 2007-2011. Epidemiol Biostat Public Health. 2014;11: e9405-1-e9405-9.

4. Savica R, Beghi E, Mazzaglia G, Innocenti F, Brignoli O, Cricelli $\mathrm{C}$, et al. Prescribing patterns of antiepileptic drugs in Italy: a nationwide population-based study in the years 2000-2005. Eur J Neurol. 2007;14:1317-21.

5. Johansen ME. Gabapentinoid use in the United States 2002 through 2015. JAMA Intern Med. 2018;178:292-4.

6. Mathieson S, Chiro M, Maher CG, LcLachlan AJ, Latimer J, Koes BW, et al. Trial of pregabalin for acute and chronic sciatica. $\mathrm{N}$ Engl J Med. 2017;376:1111-20.

7. Ben-Menachem E. Pregabalin pharmacology and its relevance to clinical practice. Epilepsia. 2004;45(Suppl 6):13-8.

8. Wiffen PJ, Derry S, Bell RF, Rice ASC, Tölle T, Phillips T, et al. Gabapentin for chronic neuropathic pain in adults. Cochrane Database Syst Rev. 2017;6:CD007938. https://doi.org/10.1002/14651 858.cd007938.pub4. http://www.cochrane.org/CD007938/ SYMPT_gabapentin-chronic-neuropathic-pain-adults. Accessed 13 June 2018.

9. Moore RA, Straube S, Wiffen PJ, Derry S, McQuay HJ. Pregabalin for acute and chronic pain in adults. Cochrane Database of Systematic Reviews 2009, Issue 3. Art. No.:CD007076. https:// doi.org/10.1002/14651858.cd007076.pub2. http://www.cochrane. org/CD007076/SYMPT_pregabalin-acute-and-chronic-pain-adult s. Accessed 13 June 2018 .

10. Chilkoti G, Wadhwa R, Saxena A, Khurana P. Could pregabalin premedication predispose to perioperative atrial fibrillation in patients with sepsis? Saudi J Anaesth. 2014;8(Suppl 1):S115-6.
11. Laville MA, de la Gastine B, Husson B, Le Boisselier R, Mosquet $\mathrm{B}$, Coquerel A. Faut-il se méfier de la prégabaline chez les patients âgés aux antécédents de troubles du rythme cardiaque? La Revue de Médecine Interne. 2008;29:152-4.

12. Martinez L, Therasse C, Ginisty S, Eftekhari P. Cardiac events and pregabalin: spontaneous reports notified to the French pharmacovigilance database. 34èmes Journées de Pharmacovigilance, Angers, 22-24 April 2013. Fundamental Clin Pharmacol. 2013;27 [suppl 1]:95 (abstract P 2-086).

13. eHealthMe, Personalized Health Information. Review: could gabapentin cause atrial fibrillation (Atrial fibrillation/flutter)? http://www.ehealthme.com/ds/gabapentin/atrial+fibrillation. Accessed 10 May 2018.

14. eHealthMe, Personalized Health Information. Review: could Lyrica cause atrial fibrillation (Atrial fibrillation/flutter)? http:// www.ehealthme.com/ds/lyrica/atrial+fibrillation. Accessed 10 May 2018.

15. Gilabert-Perramon A, López-Calahorra P, Escoda-Geli N, Salvadó-Trias $C$. Receta electrónica en Cataluña $(\operatorname{Rec} @ \mathrm{t})$ : una herramienta de salud. Med Clin. 2010;134(Suppl 1):49-55.

16. CatSalut. Informe mensual de seguiment de la prestació farmacèutica. Facturació de Farmàcia, setembre 2016. http://www.conso rci.org/media/upload/arxius/Butlleti/MaterialButlleti/InformeSeg uimentFarmacia_Set2016.pdf Accessed 10 May 2018.

17. Neurontin-Article 30 referral-Annex III. Summary of product characteristics, labelling and package leaflet. http://www.ema. europa.eu/docs/en_GB/document_library/Referrals_document/ Neurontin_30/WC500009308.pdf Accessed 10 May 2018.

18. Lyrica: EPAR—Product Information. http://www.ema.europa.eu/ docs/en_GB/document_library/EPAR_-_Product_Information/ human/000546/WC500046602.pdf Accessed 10 May 2018.

19. Billionnet C, Alla F, Bérigaud É, Pariente A, Maura G. Identifying atrial fibrillation in outpatients initiating oral anticoagulants based on medico-administrative data: results from the French national healthcare databases. Pharmacoepidemiol Drug Saf. 2017;26:535-43.

20. Schnabel RB, Yin X, Gona P, Larson MG, Beiser AS, McManus $\mathrm{DD}$, et al. 50 year trends in atrial fibrillation prevalence, incidence, risk factors, and mortality in the Framingham Heart Study: a cohort study. Lancet. 2015;386:154-62.

21. Svennberg E, Engdahl J, Al-Khalili F, Friberg L, Frykman V, Rosenqvist M. Mass screening for untreated atrial fibrillation. The STROKESTOP study. Circulation. 2015;131:2176-84.

22. Hsu JC, Maddox TM, Kennedy K, Katz DF, Marzec LN, Lubitz $\mathrm{SA}$, et al. Aspirin instead of oral anticoagulant prescription in atrial fibrillation patients at risk for stroke. J Am Coll Cardiol. 2016;67:2913-23.

23. Fuzier R, Serres I, Guitton E, Lapeyre-Mestre M, Montastruc J-L. The French Network of Pharmacovigilance Centres. Adverse drug reactions to gabapentin and pregabalin. A review of the French pharmacovigilance database. Drug Saf. 2013;36:55-62.

24. Jack A. Pfizer steps up battle to defend control of pregabalin. BMJ. 2015;350:h3119.

25. Shanthanna H, Gilron I, Rajarathinam M, AlAmri R, Kamath S, Thabane L, et al. Benefits and safety of gabapentinoids in chronic low back pain: A systematic review and meta-analysis of randomized controlled trials. PLoS Med. 2017;14:e1002369.

26. Landefeld CS, Steinman MA. The Neurontin legacy-Marketing through misinformation and manipulation. $\mathrm{N}$ Engl J Med. 2009;360:103-6.

27. Top 50 pharmaceutical products by global sales. http://www. pmlive.com/top_pharma_list/Top_50_pharmaceutical_produ cts_by_global_sales. Accessed 10 May 2018. 